\title{
PROPORTIONAL HAZARD ESTIMATION ADJUSTED BY CONTINUOUS CREDIBILITY
}

\author{
BY
}

Jens Perch Nielsen and Bjørn Lunding SAndqvist

\begin{abstract}
This paper extends the continuous credibility weighting introduced to hazard estimation in Hardy and Panjer (1998) and Nielsen and Sandqvist (2000) to the more general case, where the common basis is a proportional hazard model.
\end{abstract}

\section{KEYWORDS}

Counting process theory; Kernel hazard estimation; Continuous credibility; Bühlmann-Straub model; Proportional hazard models.

\section{INTRODUCTION}

Inspired by the credibility approach to hazard estimation of Hardy and Panjer (1998), Nielsen and Sandqvist (2000) considered hazards of different groups assuming the hazard of each group to fluctuate across a common baseline hazard. They modelled this fluctuation by a heterogeneity parameter capturing the particular properties of each group allowing for a surprisingly simple credibility estimation procedure. The new estimation procedure can extend nonparametric smoothing techniques to a number of data sets from the insurance industry or other places including, for example, credit risk, where transitions from one credit risk group to another are modelled. Nielsen and Sandqvist (2000) considered hazards of the $i$ 'th group given by

$$
\theta_{i}(t) \alpha(t)
$$

where $\alpha(t)$ is a smooth baseline intensity and $\theta_{i}(t)$ is a stochastic risk process with $E\left\{\theta_{i}(t)\right\}=1$. This model was estimated by a combination of nonparametric estimation (in the $t$-dimension) and credibility (between groups: e.g. the $i$-dimension) where information from one group is guiding estimation of hazards of other groups.

In this paper we consider the situation, where the proportional hazard model takes over in case of data sparsity instead of a common baseline hazard 
As a consequence of standard kernel hazard estimation techniques, see Nielsen and Tanggard (2001) or the appendix of Nielsen and Sandqvist (2000) we get

$$
E\left(\tilde{\eta}_{i}(t) \mid \theta_{i}(t)\right)=\{1+o(1)\} D_{i} \theta_{i}(t)
$$

and

$$
\operatorname{Var}\left(\tilde{\eta}_{i}(t) \mid \theta_{i}(t)\right)=\{1+o(1)\} C_{2} D_{i} \theta_{i}(t) \alpha^{-1}(t)\left\{b \tilde{Y}_{i .}(t, b)\right\}^{-1},
$$

where $C_{2}=\int K^{2}(u) d u$. Thus

$$
\begin{gathered}
E\left(\tilde{\eta}_{i}(t)\right)=\{1+o(1)\} D_{i}, \\
\operatorname{Cov}\left(\eta_{i}(t), \tilde{\eta}_{i}(t)\right)=\{1+o(1)\} D_{i}^{2} \sigma_{t}^{2}
\end{gathered}
$$

and

$$
\operatorname{Var}\left(\tilde{\eta}_{i}(t)\right)=\{1+o(1)\}\left[C_{2} D_{i} \alpha^{-1}(t)\left\{b \tilde{Y}_{i .}(t, b)\right\}^{-1}+D_{i}^{2} \sigma_{t}^{2}\right] .
$$

Due to the first lines in this section we can replace $\tilde{\beta}_{i}(t)$ with $\bar{\beta}_{i}(t)=\left\{D_{i}\right\}^{-1}$ $\tilde{\eta}_{i}(t) \alpha(t)$ and we conclude that

$$
\begin{gathered}
E\left\{\tilde{\beta}_{i}(t)\right\}=\{1+o(1)\} \alpha(t), \\
\operatorname{COV}\left\{\beta_{i}(t), \tilde{\beta}_{i}(t)\right\}=\{1+o(1)\} \sigma_{t}^{2} \alpha^{2}(t)
\end{gathered}
$$

and

$$
\operatorname{VAR}\left\{\tilde{\beta}_{i}(t)\right\}=\{1+o(1)\}\left[D_{i}^{-1} C_{2} \alpha(t)\left\{b \tilde{Y}_{i .}(t, b)\right\}^{-1}+\sigma_{t}^{2} \alpha^{2}(t)\right] .
$$

\section{REFERENCES}

Aalen, O.O. (1994) Effects of frailty in survival analyses. Statistical Methods in Medical Research, 3, 227-243.

Andersen, P.K., Borgan, O., Gill, R.D., and Keiding, N. (1992) Statistical models based on counting processes. Springer-Verlag, New-York.

Bickel, P.J., KlaAssen, C.A.J., Ritov, Y. and Wellner, J.A. (1993) Efficient and adaptive estimation for semiparametric models. The John Hopkins University Press, Baltimore and London.

Bühlmann, H. and Straub, E. (1970) Glaubwürdigkeit für Schadensätze. Bulletin of the Association of Swiss Actuaries, 70, 111-133.

Hardy, M.R. and PANJER, H.H. (1998) A credibillity approach to mortality risk. Astin Bulletin, 28, 269-283.

Hastie, T.J. and Tibshirani, R.J. (1990) Generalized Additive Models. Chapman and Hall.

HJoRT, N.L. (1992) Semiparametric estimation of parametric hazard rates. In Klein, J.P and Goel, P.K., editors, Survival Analysis: State of the Art. pp. 211-236. Kluwer, Dordrecht.

HougaArd, P. (2000) Analysis of multivariate survival data. Springer-Verlag, New-York.

Jones, M.C., Linton, O.B. and Nielsen, J.P. (1995) A simple bias reduction method for density estimation. Biometrika, 82, 327-38. 
Mammen, E., Linton, O.B. and Nielsen, J.P. (1999) The existence and asymptotic properties of a backfitting projection algorithm under weak conditions. Annals of Statistics, 27, 14431490.

Nielsen, J.P. (1998) Multiplicative bias correction in kernel hazard estimation. Scand. J. Statist., 11, 453-466.

Nielsen, J.P., Linton, O.B. and Bickel, P. (1998). On a semiparametric survival model with flexible covariate effect. Ann. Statist., 26, 215-241.

Nielsen, J.P. and SAndqvist, B. (2000) Credibility weighted hazard estimation. Astin Bulletin, 30, 405-417.

Nielsen, J.P. and SANDQvist, B. (2005) Correction note to "Credibility weighted hazard estimation. Astin Bulletin, 30(2), 405-417”. Astin Bulletin 35(1), 259.

Nielsen, J.P. and TANGaARD, C. (2001) Boundary and bias correction in kernel hazard estimation. Scand. J. Statist., 28.

NorberG, R (2004) Credibility theory. In: Encyclopedia of Actuarial Science, Wiley.

RAMLAU-HANSEN, H. (1983) Smoothing counting process intensities by means of kernel functions. Ann. Statist., 11, 453-466.

WoodBury, M.A. and MANTON, K.G. (1977) A randon walk model of human mortality and aging. Theor. Population Biol., 11, 37-48.

Jens Perch Nielsen and BJørn Lunding Sandqvist

Royal\&SunAlliance

Codan

Gammel Kongevej 60

1790 Kobenhavn V

Denmark

E-mail:npj@codan.dk andsan@codan.dk 